\title{
An Exploratory Study Of The Assessment Process Of The Ethical Conduct Of Top Executives In The For-Profit And Nonprofit Sectors
}

\author{
Kathy Denhardt, University of Delaware, USA \\ James L. Morrison, University of Delaware, USA \\ Audrey Helfman, University of Delaware, USA \\ Alain Noghiu, University of Delaware, USA
}

\begin{abstract}
Because this kind of study is filled with unique challenges from gaining direct access to an appropriate research sample to that of designing an innovative survey that can be completed within strict time constraints, this research may be considered exploratory in nature. Therefore, based on research findings derived from limited and constrained access to executive leadership in large publicly traded companies and their counterparts in the nonprofit sector, it was concluded that a very few organizations in either sector have a proactive ethics strategy or a formal approach to the assessment of leader ethics. Correspondingly, whatever assessment process followed, the ethical criteria for assessing top executives focuses more on their behavior as individuals rather than those aspects having a systematic organizational impact on other subordinates.
\end{abstract}

Keywords: Ethics Assessment, Ethics Strategy, Leadership

\section{INTRODUCTION}

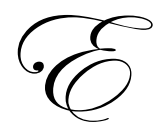

thics scandals involving top executives make the headlines on an all too regular basis, spanning all sectors and reaching across the globe. In the U.S., top executives employed in publicly traded corporations, such as Worldcom, Enron, and Tyco, and nonprofits, such as the Smithsonian Institution and the J. Paul Getty Trust, have faced accusations of financial mismanagement, fraud and/or personal ethical failures ${ }^{1}$. With public outrage mounting over the unethical conduct of top executives, attention to organizational efforts to assure their accountability are coming under closer scrutiny. When considering holding top executives of organizations accountable for their ethical conduct, three external factors come into play.

1. The Federal Sarbanes Oxley Act of 2002 (SOX) has been part of a highly visible effort by public sector agencies to strengthen accountability among corporate executives. SOX requires that publicly traded corporations adopt a code of ethics ("such standards as are reasonably necessary to promote... honest and ethical conduct") or explain publicly why they do not have one. Though SOX provisions apply primarily to publicly traded corporations, some recognize their importance to top executives in the nonprofit sector also, resulting in the possibility of nonprofits voluntarily adhering to these guidelines as well ${ }^{3}$. States like California are imposing provisions similar to SOX on nonprofits (Gilkerson, 2007), and there is some indication those in nonprofit organizations are proactively adopting policies, such as enhancing independent audits and improving board oversight practices (Grunewald, 2007).

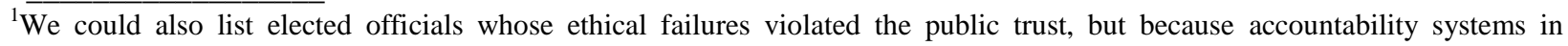
government are so different from those in business and nonprofit organizations we do not address them in this research. However, it is important to acknowledge that ethical failures of senior leaders span all sectors.
} 
2. To deter organizations, as well as individuals, from engaging in unethical activities, Organizational Sentencing Guidelines promulgated by the U.S. Sentencing Commission, an independent agency in the Judicial Branch of the Federal Government, are currently used to deter criminal activity by reducing fines for organizations that can demonstrate compliance standards and procedures that are reasonably capable of reducing the prospect of criminal activity. For example, in 2004, in the wake of Enron (an organization that on the surface had complied with these guidelines), the Sentencing Commission not only made clear that token or paper compliance was not sufficient to relieve liability, but also made ethical accountability explicit in its statement that an "organization shall...otherwise promote a workplace culture that encourages ethical conduct and a commitment to compliance within the law" (Fiorelli, 2004, p. 565).

3. Recent court rulings also substantiate that oversight is an organization's duty and relates to their leadership being informed in making decisions and overseeing the management of the organization (Reese \& Compton, 2007). Accordingly, in 2006 the Delaware Supreme Court in Stone v Ritter clarified the Caremark standard by stating that an organization's failure to exercise reasonable oversight in good faith constitutes a breach of the duty of loyalty, and if proven, current leadership face personal monetary liability (Reese \& Compton, 2007).

While these externally imposed pressures are likely to influence top executives to be attentive to ethical and legal issues, Rhode (2006) suggests that it is actually organizational expectations that determine whether day-today actions are truly in line with ethics and the law. Ironically, in a 2002 American Management Association study, about one-third of the executives believed that their company's public statements on ethics sometimes conflicted with internal messages and realities. However, considerable research suggests that leaders in organizations play a critical role in setting the ethical tone for their organizations (Verschoor, 2006).

In addition, while theories differ about how ethical leadership comes about, there are strong suggestions that the assessment process is an important part of the equation (Van Wart, 1995). In other words, organizations that assess leaders on their ethical conduct are more likely to achieve higher ethical standards (Cardy \& Selvarajan, 2006). Outcomes, however, are dependent on an organization's level of awareness of ethical issues, industry codes of conduct, and organizational cultures (Mosberg, 2006).

The particularly unique approach of this study aims to present a comparative analysis of the assessment process of leaders in senior leadership positions in both publicly traded corporations and in nonprofit organizations. These are two arenas in which there has been much attention by government officials and the mass media as to how to assure that leaders demonstrate the ethical values expected by society.

\section{LITERATURE REVIEW OF THE ETHICAL ASSESSMENT PROCESS}

Several researchers have claimed that unethical conduct has become the most important problem facing American companies today (Pomeroy, 2006). In this regard, the Sarbanes-Oxley Act (SOX) sets the standards high in terms of how publicly traded corporations are expected to address ethical issues of their leadership who are ultimately responsible for assuring a quality environment in which to work (Lipman, 2005). According to Koestenbaum (2005), an important challenge for organizations is the creation of a positive ethical tone at the top that results in promoting appropriate ethical conduct throughout an organization. He argues that deterring misconduct before it takes place is better than punishing it after the damage has been done. Koestenbaum points out that any organization can establish a code of ethics; but without its leadership promoting an ethical environment on a daily basis, the impact of the code of ethics will be negligible. One proactive approach to achieving the right ethical environment at the top is a comprehensive annual assessment of the ethical performance of leaders in senior management.

Along the same line of thought, Lipman (2006) argues that the key to creating an ethical work culture is to annually assess leaders using the highest of ethical standards. Lipman also points out that the U.S. Department of Justice currently requires the leadership in publicly traded companies to create an ethical, law-abiding culture to avoid criminal indictment. Lipman thus recommends that financial incentives be provided to create such a culture. Holding the leaders of an organization accountable for their behavior through a yearly assessment process is critical for establishing a framework for providing such incentives in the overall executive compensation scheme. 
Warren Bennis (2003), founder of the Leadership Institute at the University of Southern California's Marshall School of Business, argues that leaders are those who create a climate of candor and trust throughout their organizations. Similarly, Trevino, et. al. (1999), also documents the impact that leadership has upon organizational culture. In referring to a recent landmark study on dimensions to ethical management, Trevino, et. al., agree with the study's conclusion that shared norms and beliefs which guide individual and organizational behavior are directly shaped by the leaders of an organization (Trevino, et.al., 1999). A working paper published by the Ethics Resource Center ERC Fellows Program reinforces the notion that senior leadership plays a vital role in building and fostering an ethical environment in an organization (Daigneault, et. al., 2000). The paper points out that ethics officers (very common in business, less so in nonprofits) typically focus their attentions downward in the organization but that senior leadership is somewhat exempt from such scrutiny

As to actual organizational practices, some researchers claim that typical annual performance assessments of CEOs involve a cursory review of performance and automatically result in relatively standard pay increases (Ethics Policy Center, 1999). While there is some indication that more organizations are beginning to require and implement formal measurable evaluation systems for their senior leadership, based on better defined criteria, little information is available on such ethics assessment strategies for senior leadership (Ethics Policy Center, 1999).

Some business consultants have started responding to this need by offering ethics assessment and training programs. But ethics assessment practices for executive level leaders remains an under-researched area, and little information exists about what practices are being followed. An incentive for filling this information gap is a growing acceptance of the perspective put forth by the Ethics and Policy Integration Center's (EPIC) website; that being, "the dominant thinking in organizational life is that if you cannot measure it, it isn't important;" and "what is measured is what tends to get attention and resources" (http://ethicaledge.com/queset_7.html). In this regard, Selvarajan (2006) reinforces the perspective that formally assessing the ethical conduct of an organization's leader elevates ethics expectations and thus makes ethical conduct at work an integral part of everyday operations.

Van Wart (2005) suggests that ethical assessments generally focus on either determining how an organization is adhering to specified legal norms or evaluating the way leaders are personally promoting ethical guidelines.. To Van Wart, the former is best determined by an independent ethics audit of some kind and the latter by a formal ethical assessment as part of a performance review. Moreover, in a talk at the Markkula Center for Applied Ethics, James O'Toole (2004) suggests that any assessment of ethical conduct of employees should begin with an analysis of the CEO. Issues to be addressed are ethical reputation of the CEO, the communication of expectations of ethical behavior, the degree of ethical training available to employees, the system in effect to report ethical violations and concerns, and rewards in place for those exhibiting highest standards of ethical conduct.

According to Valenti (2002) and Lebovitz (2006), SOX has resulted in enhancing the likelihood that an ethical work culture based on action rather than discussion will occur. They state that ethical decision-making starts at the top with a leadership which motivates others to emulate the behavior of the CEO. In this regard, leaders must be able to speak openly about their views on the value of ethical behavior and, more importantly, behave accordingly themselves. Rewarding such actions through an annual assessment process can have a positive influence upon the work culture in an organization. A substantial body of literature focuses on other factors that might impact the outcomes of ethics assessment strategies, such as gender, cognitive processes, motivational factors, culture, and people's position in the organization (Beutell \& Brenner, 1986) (Hodson, 1989) (Greenberg, 1988). As a result of a detailed literature search, the study reported here appears to be the first of its kind that primarily focuses attention on the specifics of the annual assessment process of senior leadership on their ethical conduct.

\section{Research Design}

This research presented several significant challenges for getting data from sources who would be readily available for access and response. In this regard, since the board of directors is typically responsible for evaluating chief executives in both the for-profit and nonprofit sectors, it would have been preferable to gather information directly from them about what they are doing to assess ethical performance of senior executive leadership. By design, however, boards in the for-profit sector systematically establish procedures to isolate themselves from direct contacts from the public. In addition, many organizations have put into place formal procedures that make it 
extremely difficult for researchers to contact them for the purpose of responding specifically to surveys. Given the difficulty of getting information directly from the boards responsible for assessing executive leadership, alternate means had to be devised for gathering data. Thus, it was determined to gather information by querying top executives (equivalent of the title of CEO) in publicly traded corporations and the Executive Director or equivalent in nonprofit organizations. Very poor response rates from the for-profit sector chief executives made it necessary for us to pursue a secondary strategy of data gathering for that sector. In the event that the for-profit organization had an ethics or compliance officer, the survey was sent to this officer in order to gain insight as to how organizations assess their senior leaders on their ethics.

In addition, gathering data about two dimensions to assessment presented another challenge. Whereas an expert panel of 5 current CEOs (or equivalent) revealed that a metric used for assessing the annual economic performance of a chief executive is a common occurrence, no such metric is likely to be available in the formal measurement of ethical conduct. Therefore, the panel suggested that there is a need for a two-level approach for examining the assessment process of the senior leadership; that being, a formal and informal process. For this study, a formal process is defined as an assessment of the ethical performance of a top executive during a one-time specific annual performance review, using a specific metric. An informal process relates to determining the effectiveness of a top executive in addressing ethical situations systematically as they arise throughout the year. In other words, ethical conduct of senior leaders is judged on a case-by-case basis by other means than applying a specific metric to assess such performance.

Since top executives of large publicly traded companies and those in large nonprofit organizations are under severe time constraints for carrying out their primary responsibilities, it was determined that an efficient and less time consuming data collection strategy was required. For designing the strategy for collecting meaningful data for the research, a panel of 5 leaders of which three were currently CEOs in publicly traded companies and 2 executive directors in nonprofit organizations was used. This panel also played instrumental roles in putting together items for the online survey utilized in this study.

\section{ONLINE SURVEY INSTRUMENT DEVELOPED}

It was determined that an online survey requiring no more than 10 minutes to complete would be the most appropriate mechanism for gaining access to credible information from chief executives. The first segment of the online survey consisted of items for gathering demographic data. For the second segment of the online survey, a 5point rating scale ( +2 to strongly agree, 0 for no opinion, and -2 for strongly disagree) was used to collect data relating to the current organizational environment in which the assessment of ethical conduct is administered. The third segment consisted of items related to specific criteria (or benchmarks) utilized in assessing a leader's ethical performance. The last segment of the survey related to identifying actual assessment practices followed by publicly traded corporations and nonprofit organizations.

The items for the survey instrument were gathered as a result of a literature review on assessment practices in addition to interviews with a panel of experts consisting of three top executives in publicly traded organizations and two from large nonprofit organizations. Therefore, the survey instrument developed has face validity in that the instrument reflects items reviewed by top executives who were not part of the sample used for the study. The panel of experts suggested that we adopt a unique strategy in order to get a response from those senior leaders needed to develop the sample population for the study. It was their perspective that individuals holding high positions in leadership would not respond to a typical written survey. However, in its place, the panel suggested that CEOs and executive directors, because of their adeptness in using the Internet, would more likely respond to an online data collecting instrument delivered by means of the Internet. In this regard, having to enter a new realm for collecting data from difficult to access individuals helped define this research as more exploratory rather than a final product. The process for selecting the sample for this exploratory study is presented directly below.

\section{Sample Selection}

To have an acceptable degree of symmetry among the organizations whose leadership assessment processes are to be compared, we focused on the 200 largest publicly traded companies and the 200 largest nonprofit 
organizations. Specifically, we used the top 200 U.S. companies from the Forbes 2007 list of the World's 2000 Largest Public Companies, which were ranked based on measures of sales, market value, assets and profits (Forbes, 2007). We also utilized the Forbes 2006 list of America's 200 Largest Charities, which ranked nonprofits on the basis of private gifts reported, and which excluded academic institutions (Forbes, 2006).

Senior leaders (the CEO, Executive Director, or equivalent) were initially contacted by a formal letter seeking their agreement to participate in the study. A subsequent email message was sent to these same participants requesting that the respondents access the online survey by a link provided in that email. Two subsequent email communications were made in order to generate additional responses. In the case of for-profit organizations a subsequent letter was sent to the organization's ethics compliance officer requesting their response to the survey.

\section{Findings and Discussion}

Based on an electronic survey sent in March 2007 to top executives (CEO's) of the largest 200 U.S. publicly traded corporations, and the Executive Directors of the largest 200 U.S. nonprofits, data was collected from and subsequently analyzed for 81 respondents. Of the 81 respondents, 52 were affiliated with nonprofit organizations (a $26 \%$ response rate) and 29 with publicly traded companies (a 15\% response rate). In the publicly traded companies, 19 top executives were male; 10, female. In the nonprofit sector, 33 executives were male; 19 , female. In terms of title, in the publicly traded companies, 19 were identified as CEO and 10 as president. In the nonprofit sector, 42 were identified as executive director, and 10 held a variety of other leadership titles.

Of the 52 responding organizations in the nonprofit sector, the majority were from three kinds of organizations: fourteen with a general human services orientation, eight with a religious affiliation, and eight with a health care focus. In the 29 publicly traded companies responding, nine were associated with manufacturing, six with retailing, and four with financial services.

Organizational Expectations (Norms) Related to Ethical Aspects of Employment. In Table 1, the current organizational ethical norms (or existing framework) of nonprofit organizations and publicly traded companies are delineated. In this regard, mean scores are derived from responses on a 5-point rating scale in which +2 indicates strong agreement; 0 , a neutral response; and -2 indicating strong disagreement. Leaders from the for-profit sector (FP) take significantly stronger positive positions than those in the nonprofit sector (NP) regarding having a rigorous ethics enforcement policy ( $\mathrm{FP}=1.692 ; \mathrm{NP}=1.030)$, openly posting of codes of conduct $(\mathrm{FP}=1.884 ; \mathrm{NP}$ $=1.182$ ), and being formally responsible to ensure ethical conduct within the organization $\mathrm{FP}=1.192 ; \mathrm{NP}=0.455)$. In terms of openly posting vision, values and codes of conduct, it is reasonable to expect that publicly traded organizations would respond very positively since they are subject to the Sarbanes-Oxley Act which requires that their organization adopt a code of ethics or explain publicly why they have not done so. Nonprofits are not subject to this provision of SOX, though some no doubt voluntarily adopt a code of ethics. However, leaders in both sectors disagree that their intent in adopting such practices is to only meet legal mandates.

While respondents to our survey from both sectors tend to agree that they have a code of ethics, they agree to a lesser extent whether they have a rigorous ethics enforcement policy. This suggests that even if a code of ethics is in place, enforcement is lagging behind. Weaker still is agreement from both sectors to the question of top executives being responsible to ensure the ethical conduct of others.

Interestingly, leaders responding to the online survey instrument in our study were generally neutral in their perceptions that their organizations had implemented a formal process to assess ethical conduct of executives $(\mathrm{FP}=$ $0.692 ; \mathrm{NP}=0.485)$ and that their organizations were proactive in promoting ethical strategy among its leaders $(\mathrm{FP}=$ 0.501; NP = 0.101). Since the findings indicate that organizations may not have formal ethical performance assessment matrices in effect, our survey included a question about the use of external consultants to assist with this endeavor. However, leaders in both for-profit and nonprofit organizations disagreed to a similar degree that their organizations rely upon external assessment consultants to evaluate performance of top executives $(\mathrm{FP}=-0.501$; NP $=-0.303)$. 
Table 1

Comparison of Assessment Norms by Organizational Type (ANOVA)*

\begin{tabular}{|c|c|c|c|c|c|}
\hline \multicolumn{2}{|r|}{ Organizational Expectations (Norms) } & \multicolumn{2}{|c|}{ Means } & \multirow[t]{2}{*}{$\mathbf{F}$} & \multirow[t]{2}{*}{ Prob. } \\
\hline & & $\mathbf{F P} * *$ & $\mathbf{N P} * *$ & & \\
\hline 1 & Work Procedures. Equally Import. As Outcomes & 1.846 & 1.545 & 1.18 & .283 \\
\hline 2 & Rigorous Ethics Enforcement & 1.692 & 1.030 & 11.06 & $.002 * * *$ \\
\hline 3 & Openly Posting of Code of Conduct & 1.884 & 1.182 & 11.67 & $.001 * * *$ \\
\hline 4 & Leaders Resp. to Ensure Ethical Conduct t/o Org. & 1.192 & 0.455 & 4.47 & $.039 * * *$ \\
\hline 5 & Leaders Must Sign Ethics Compliance Statement & 1.269 & 0.727 & 0.90 & .348 \\
\hline 6 & Org. Promotes Proactive Ethics Strategy & 0.501 & 0.101 & 1.35 & .251 \\
\hline 7 & Formal Assessment Process Followed & 0.692 & 0.485 & 0.01 & .926 \\
\hline 8 & Need to Meet Legal Mandates & -0.808 & -0.606 & 0.99 & .323 \\
\hline 9 & Rely Upon External Consultant for Ethics Assessment & -0.501 & -.303 & 0.37 & .544 \\
\hline & $\begin{array}{l}\text { Rating Scale }:+2=\text { Strongly Agree } ; 0=\text { Neutral } ;- \\
* \text { ANOVA - Analysis of Variance } \\
* * F P=\text { For-Profit (Publicly Traded Companies) } ; \\
* * * \text { Statistical Significant at } .05 \text { Level }\end{array}$ & $\begin{array}{l}\text { isagree } \\
\text { it Organi }\end{array}$ & & & \\
\hline
\end{tabular}

Criteria Utilized to Formally Assess Ethical Conduct of Top Executives. Based on the ranking of the frequency of criteria used to assess ethical conduct on an annual basis, there is noticeable similarity across sectors among standards adopted. The findings indicate that a formal process in both sectors includes basically the application of two criteria: the promotion of core values and setting a good personal example (See Table 2).

The findings also indicate that the four least utilized performance criteria for assessing ethical conduct of those in senior leadership positions were initiating of ethics education/training, promoting social responsibility, put safeguards into place and monitoring the ethical practices of others. In terms of the formal assessment process, it appears that leaders are being assessed more on their personal individual behavior (personal example), and less on their impact on others or the organization's culture as a whole (monitoring ethical practices of others, education/training, creating safeguards). Thus the findings indicate that an assessment focus appears to be on individual performance rather than on overall organizational effect. Though those in senior leadership positions in large organizations such as those we studied indicate a responsibility for implementing safeguard systems to assure the ethical conduct of all members in an organization, a formal assessment of such an expectation appears to be minimal, if any.

Table 2

Ranking of Criteria Explicitly Included in a Formal Annual Assessment of Executives in Senior Leadership Positions by Organizational Type $(\mathrm{NP}=52)(\mathrm{FP}=29)$

\begin{tabular}{|c|c|c|c|c|c|}
\hline \multicolumn{2}{|r|}{ Assessment Criteria } & NP* & Rank** & FP* & Rank** \\
\hline 1 & Promotes Core Ethical Values & 42 & 1 & 20 & 1 \\
\hline 2 & Sets a Good Personal Example & 38 & 2 & 15 & 2 \\
\hline 3 & Assures Legal Mandates Meet & 17 & 3 & 7 & 4 \\
\hline 4 & Ensures Safety of Employees & 11 & 4.5 & 10 & 3 \\
\hline 5 & Puts Safeguards into Place & 11 & 4.5 & 1 & 7.5 \\
\hline 6 & Initiates Ethics Education and Training & 3 & 8 & 2 & 6 \\
\hline 7 & Promotes Social Responsibility & 6 & 6 & 1 & 7.5 \\
\hline 8 & Monitors Ethical Practices of Others & 5 & 7 & 4 & 5 \\
\hline
\end{tabular}

Note: *NP-Nonprofit (52); FP-For-Profit (Publicly Traded Company) (29)

$* *$ Coefficient of Rank Correlation $(r=.729 ; p=.040)$

Criteria Utilized to Informally Assess Ethical Conduct of Top Executives. The findings related to adopting an ethical performance assessment matrix as part of an informal process also appear to be minimal (see 
Table 3). A reliance upon a limited assessment matrix via informal assessment process is also very similar across sectors. Since the informal assessment process brings attention to ethical conduct on a case-be-case incident, the promoting of core ethical values and setting a good personal example appear as the two most frequently utilized criteria as part of this review. The three least utilized criteria used informally are: assures legal mandates are followed, monitoring the ethical practices of others, and initiates ethics education and training program.

Table 3

Ranking of Criteria Applied in the Informal Assessment of Executives in Senior Leadership Positions by Organization Type (NP=52) $(\mathrm{FP}=29)$

\begin{tabular}{|c|c|c|c|c|c|}
\hline \multicolumn{2}{|r|}{$\begin{array}{r}\text { Assessment Criteria } \\
\end{array}$} & NP* & Rank** & FP* & Rank** \\
\hline 1 & Promotes Core Ethical Values & 28 & 1 & 18 & 1 \\
\hline 2 & Sets a Good Personal Example & 26 & 2 & 14 & 2 \\
\hline 3 & Ensures Safety of Employees & 19 & 3 & 6 & 4 \\
\hline 4 & Puts Safeguards into Place & 13 & 5 & 7 & 3 \\
\hline 5 & Promotes Social responsibility & 14 & 4 & 5 & 5 \\
\hline 6 & Assures Legal mandates Met & 13 & 6 & 3 & 7.5 \\
\hline 7 & Initiates Ethics Education and Training & 10 & 7 & 4 & 6 \\
\hline 8 & Monitors Ethical Practices of Others & 8 & 8 & 3 & 7.5 \\
\hline
\end{tabular}

Note: $* N P=$ Nonprofit (52); $P=$ - for profit (29); ** Coefficient of Rank Correlation $(r=.886 ; p=.005)$

The findings indicate that organizations are applying a limited ethical assessment matrix as part of a complementary informal process. However, several leaders indicated the value of the informal assessment of ethical conduct adds an important dimension the complements a formal process. They suggest that if a leader is identified as demonstrating unethical behavior, it is too late. Unethical behavioral needs to be detected and stopped immediately. Therefore, the objective is to catch unethical conduct at its beginning and not wait until a formal annual assessment is made to correct the behavior pattern.

Practices Utilized to Assess Those in Senior Leadership Positions. Comparing the ranking of the frequency of actual practices used to assess ethical conduct, there is considerable similarity of those utilized by organizations in both the nonprofit and for-profit sectors ( $\mathrm{r}=.685$, see Table 4). In this regard, the four most frequently utilized practices for assessing the ethical conduct of those in senior leadership positions in these two sectors include having executives sign a statement of agreement to abide by an ethical code of conduct, relying on an internal process for actually assessing the ethical conduct of leadership, using a self-rating metric and noting the number of ethical complaints received throughout the previous year.

Table 4

Ranking of Assessment Practices Utilized by Organizational Category (NP=52) (FP=29)

\begin{tabular}{|c|c|c|c|c|c|}
\hline \multicolumn{2}{|r|}{$\begin{array}{r}\text { Assessment Practice } \\
\end{array}$} & NP & $\operatorname{Rank}^{* *}$ & FP & Rank** $^{*}$ \\
\hline 1 & Sign a Statement of Agreement to Honor Code & 17 & 3 & 19 & 1 \\
\hline 2 & Assessed by Group Internal to Organization & 19 & 1 & 10 & 2 \\
\hline 3 & Use a Self-Rating Metric & 18 & 2 & 6 & 4 \\
\hline 4 & Calculate Sum Total of Complaints Rec'd & 14 & 4 & 9 & 3 \\
\hline 5 & Assessed by Group External to Organization & 8 & 6 & 5 & 5 \\
\hline 6 & Use Assessment Metric of Board of Directors & 9 & 5 & 2 & 6.5 \\
\hline 7 & None Applied & 2 & 7 & 2 & 6.5 \\
\hline
\end{tabular}

Note: $* N P=$ nonprofit (52); $P=$ - for profit (29)

$* *$ Coefficient of Rank Correlation $(r=.685 ; P=.09)$

Interestingly, the least relied upon assessment practice was a dependence upon information derived from an assessment metric administered by the board of directors group. This response is rather surprising since the 
Sarbanes-Oxley Act focuses upon bringing accountability of the ethical conduct of leaders under closer supervision of an organization's board of directors in publicly traded organizations.

Specific Assessment Benchmarks Used in Annual Performance Reviews. In regards to the ranking of benchmarks used in assessing those in senior leadership positions, there was not a particularly strong relationship between responses in the two sectors $(\mathrm{r}=.437)$. Leaders in nonprofit organizations ranked using the number of legal compliance complaints as their most frequently utilized assessment benchmark, while those in the publicly traded companies ranked this measure fifth. In addition, leaders in the for-profit sector ranked effectiveness in completing ethical investigations among the top four most frequently used benchmarks while those in the nonprofit sector ranked this at the bottom of their listing (See Table 5).

Table 5

Ranking of Assessment Benchmarks Utilized by Organizational Type

\begin{tabular}{|c|c|c|c|c|c|}
\hline \multicolumn{2}{|r|}{ Assessment Measures } & $\mathbf{N P}$ & Rank** $^{*}$ & FP & Rank** \\
\hline 1 & No. of Ethics Complaints Received & 17 & 2.5 & 18 & 1 \\
\hline 2 & No. Legal Compliance Complaints & 22 & 1 & 13 & 5 \\
\hline 3 & Percent Signing code Agreement & 17 & 2.5 & 17 & 2 \\
\hline 4 & Percent Compliance Ethical Training & 13 & 4 & 16 & 3.5 \\
\hline 5 & Completing Ethics Investigations & 4 & 8 & 16 & 3.5 \\
\hline 6 & Response to Int. Ethics Complaints & 10 & 6 & 9 & 6.5 \\
\hline 7 & Quality of Information Available & 6 & 7 & 8 & 8 \\
\hline 8 & Response to Ext. Ethics Complaints & 3 & 9 & 9 & 6.5 \\
\hline 9 & None Apply & 12 & 5 & 5 & 9 \\
\hline
\end{tabular}

Note: $*$ Nonprofit $($ NP $)=52 ;$ For Profit $($ FP $)=29$

$* *$ Coefficient of Rank Correlation: $r=.437 ; p=.199$

There were also notable differences in responses in the two sectors regarding how timely a leader was in responding to external ethics complaints. Executive directors in nonprofit organizations ranked timeliness of responses the least frequently used benchmark, while those in the publicly traded companies ranked this higher (a 6.5 ranking). This is just one example of organizations in the for-profit sector having a more rigorous ethics policy that is also likely to be enforced more rigorously (as a priority) than those in the nonprofit sector. Interestingly, the for-profit sector reports that the number of ethics complaints received is the assessment benchmark most frequently used by the organization, while those in senior leadership positions in nonprofit organizations similarly indicate the number of legal compliance complaint as most frequent benchmark utilized..

\section{CONCLUSIONS}

Based on the findings of this study, there are some significant differences and also intriguing contradictions among senior leaders in non-profit organizations and in publicly traded companies in their perceptions as to how their ethical conduct is assessed. CEOs in publicly traded companies more strongly agree that they have a rigorous ethics enforcement process than do senior leaders in the nonprofit sector. However, there appears to be a contradiction among those in senior leadership positions in regards to how proactive their organizations are. In this regard, leaders in both groups are generally neutral in their reaction to whether their organizations have a proactive ethics strategy or a formal process in place to assess the ethical conduct of their senior leaders. It therefore may be concluded that organizational ethical expectations for their leaders are in reality high, but these expectations are reflected through organizational codes of conduct agreements rather than derived from rigorous, annual proactive assessment strategies (whether formal or informal) already being in place for assurance.

In this regard, it may be concluded that both limited formal and informal assessment processes have been adopted to assess the ethical conduct of senior leaders in both groups. In this instance, there appears to be a reliance upon a minimal assessment matrix, primarily consisting of two criteria, as part of this complementary assessment process. While the literature indicates that the economic performance of senior leaders is carried out by measuring 
success against a comprehensive matrix, no such formal or informal matrix exists when assessing the ethical conduct.

In terms of practices followed, senior leaders in both groups tend to rely on the signing of an organizational code of conduct agreement and the completion of a self-rating. What might be of greatest concern in our findings, however, is that the criteria used to assess the ethical performance of top executives in both sectors focus on individual behavior/conduct with little emphasis on leadership influencing the overall work culture of the organization and the behavior of people throughout the organization. This contradicts leadership literature that emphasizes the importance of the top executives' roles in creating an ethical culture in their organizations.

Moreover, it does appear that external influences (e.g. the Sarbanes-Oxley Act and other regulatory measures over several decades) have led publicly traded organizations to adopt formal ethics codes, have their CEOs sign a pledge to uphold the code, and post the code prominently. The nonprofit sector, although not required to comply with SOX, appears to be implementing procedures voluntarily as well (though not to the extent of businesses that are required to do so). However, there is clearly a need to develop more comprehensive formal and informal assessment metrics to assess ethical behavior of senior leadership in organizations.

Therefore, it may be concluded that organizations are not implementing comprehensive assessment practices and criteria for holding their senior leaders accountable for their ethical conduct. In spite of guidelines being development by Federal agencies, senior leaders in organizations perceive only a minimal effort being made to change practices, criteria, or benchmarks for such an assessment. The rigor of organizations to putting in place new and more detailed assessment processes, whether formal or informal, does not match the intent of the SarbanesOxley Act of 2000. In this regard, organizations might wish to be more proactive in implementing both formal and informal assessment processes to avoid future legal rules and regulations to do so. Having organizations take a more thorough and systematic approach to assessing the ethical performance of top executives might be very helpful in rebuilding that public trust and better serving the interests of stockholders and stakeholders.

Moreover, it appears that organizations are relying on baseline expectations that leaders are basically ethical and there is no need to integrate new accountability practices, etc., in any new aggressive formal or informal process. As situations challenging ethical conduct arise, leaders will be scrutinized at that moment, possibly reflecting a reliance on crisis management as the strategy for holding individuals accountable. It may be that the derived punishment (or action taken against a leader found guilty of unethical conduct) is perceived as providing the necessary deterrence (or example) to get others not to entertain similar unethical conduct.

\section{LIMITATIONS TO STUDY}

This study is an initial attempt to devise a strategy and approach for collecting data from individuals who typically are difficult to access. As a result, the spontaneous response via online resulted in a modest response rate (15\% in publicly traded companies and $25 \%$ for nonprofit organizations) reflecting the difficulty in accessing senior leaders in organizations. The response rate remained low in spite of two subsequent email attempts to contact each senior leader on the Forbes 2007 list. However, these limitations notwithstanding, the findings reported in this research begin to shed light on organizational oversight of senior executive ethical leadership. Since the response rates were low, at best these findings should be interpreted as providing a glimpse, though interesting and somewhat unique, as to what is happening in the large publicly traded companies and nonprofit organizations in the U.S. In other words, the exploratory nature of this research has set the stage for a more in-depth investigative process to verify the reliability of the data collected in this piece.

\section{AUTHOR INFORMATION}

Dr. Morrison conducts research in the areas of ethical assessment and innovation and decision-making. He has published over 75 manuscripts in journals within the disciplines of business, education, and public policy. He is currently on the editorial board of three national journals. He teaches leadership development primarily for undergraduates at the University of Delaware who are seeking careers in either the public, non-profit, or for-profit sectors. 
Dr. Denhardt conducts research in the areas of ethics, conflict resolution, and collaborative problem-solving. She has published mainly in journals within the disciplines of public administration, non-profit organizations, and community service. She teachers primarily in the graduate school of urban affairs at the University of Delaware. She is known for her outstanding work with community groups for enhancing the quality of life of neighborhoods primarily in urban centers.

Dr. Helfman conducts research in the area of women leadership issues. She primarily teaches undergraduates at the University of Delaware, focusing upon courses that establish a foundation for the study of leadership for majors and others throughout the campus. She has led an around-the-world study abroad program for the past three years, leading students in a learning experience that is quite unique. She is known for her innovative teaching style and dynamic approach to analyzing gender issues in leadership.

Alain Noghiu is a doctoral candidate in urban affairs at the University of Delaware. He comes from the Netherlands and is currently analyzing public policy from an international perspective. He plans to complete his dissertation during the Spring 2009.

\section{ACKNOWLEDGEMENTS}

Appreciation to Charles Elson, Director of the Weinberg Center for Corporate Governance, University of Delaware, for sharing his insights with us on factors influencing corporate boards.

\section{BIBLIOGRAPHY}

1. Bennis,W (2003) A Cognitive Processing Model for Assessing Ethical Behavior in Employees. (New York, NY: Bennis Books)

2. Beutell,N \& Brenner, O. (1986). Sex differences in work values. Journal of Vocational Behavior, 28, pp. 29-41.

3. Bridges, J. (1989). Sex differences in occupational values. Sex Roles, 20, pp. 205-211.

4. Cardy,Robert L.\& Selvarajan, T. (2006). Assessing ethical behavior: The impact of outcomes on judgment bias. Journal of Managerial Psychology, 21, pp. 52-72.

5. Daigneault, Michael G; Guthrie, Jerry D; and. Navran, Frank J,. 2000). Managing ethics upward. ERC Fellows Program Working Paper. (Washington, DC: Ethics Resource Center,) p. 5

6. Daigneault, (et. al.,) ibid., p. 9.

7. Ethics and Policy Integration Center (1999). Measuring organizational integrity, and the bottom line results one can expect. Retrieved from the web on September 21, 2006 .http://www.epic-online.net lquest_7.html

8. $\quad$ Ethics and Policy Integration Center (1999). Ibid, pg1 (Website http://www.ethicaledge.com/quest_7.html

9. Fiorelli, Paul (2004). Will U.S. Sentencing Commission Amendments encourage a more ethical culture within organizations? Wake Forest Law Review, 39 , pp. 565-586 Retrieved from the Web on March 6, 2007. http://www.law.wfu.edu/prebuilt/Fiorelli- final.pdf

10. Forbes, (2007).World's 2000 Largest Public Companies" (2007). Retrieved from The web on Aprill, 2007. http://www.forbes.com/2007/03/29/forbes-global-2000-biz-07forbes2000cz_sd 0329global_land.html.

11. Forbes . (2006). America's 200 Largest Charities" (2006). Retrieved from the web on January 7, 2007 http://www.forbes.com/lists/2006/14/pf_phil_06charities_The-200-Largest-U.S.-Charities_TotalRev.html

12. Gilkerson,Nicole (2007). For-profit scandal in the nonprofit world: Should states force Sarbanes-Oxley provisions onto nonprofit corporations? The Georgetown Law Journal, 95, pp. 831-854.

13. Greenberg, J (1988). Equity and workplace status: a field experiment. Journal of Applied Psychology, 73, pp. 606-13.

14. Grunewald, Donald (2007). The Sarbanes-Oxley Act will change the governance of nonprofit organizations. Journal of Business Ethics, 80, No. 3, pp. 399-401.

15. Hodson, R. (1989). Gender difference in satisfaction: why aren't women more dissatisfied? Sociological Quarterly, 3, pp. 385-99; 
16. Independent Sector and Board Source, (2006). The Sarbanes-Oxley Act and implications for nonprofit organizations. Retrieved from the Web on March 5, 2007.

http://www.independentsector.org/PDFs/sarbanesoxley.pdf, (http://www.ussc.gov/corp/orgoverview.pdf).

17. Koestenbaum, P. (et. al.) (2005). Integrating Sarbanes-Oxley, leadership, and ethics. The CPA Journal, p. 75.

18. Lebovitz,Neil (2006). Beyond Sarbanes-Oxley: three best practices to adopt in your organization,” Journal of Accountancy, p 202.

19. Lipman,Frederick D. (2006). The ten best practices for audit committees. Financial Executive, pp. 49-51

20. Mosberg, Dennis J. (2006). Ethics blind spots in organizations: How systematic errors in personal perception undermine moral agency. Organization Studies, 27, pp. 413-428

21. O'Toole, James (2004). The ethical challenges in human resources. Markkula Center for Applied Ethics, Santa Clara University, CA. 2004. Retrieved from the web on September 7, 2006.

http://www.scu.edu/ethics/practicing/focusareas/business/ethics-human-resources.html

22. Pomeroy (2006) in The Theory and Practice of Power, Judgment, and Policy, Deborah L. Rhode (ed.) (San Francisco: Jossey-Bass,) p. 23.

23. Reese, Cathy L. and Compton, Kyle (2007). When loyalty means liability. Boardroom Intelligence. Retrieved from the web on November 6, 2007. http://www.directorship.com/when-loyalty-means-liability .

24. Reese and Compton (2007). Ibid., p: 1.

25. Rhode,Deborah L. (2006). Introduction: Where is the leadership in moral leadership. pp. 1-53. In Deborah L. Rhode (ed). Moral Leadership: The Theory and Practice of Power, Judgment, and Policy, (San Francisco, CA: Jossey-Bass, 2006)

26. Selvarajan, T. (2006), A cognitive processing model for assessing ethical behavior of employees. Journal of American Academy of Business, 19, pp. 86-93.

27. Trevino, Linda K., (et. al.) (1999). Managing ethics and legal compliance: What works and what hurts. California Management Review,41, pp.131-151

28. Valenti, Alix (2007). The Sarbanes-Oxley Act of 2002: Has it brought about changes in the boards of large U. S. corporations? Journal of Business Ethics, pp. 76

29. Van Wart, Montgomery (1995). The first step in the reinvention process: assessment. Public Administration Review, 55 , pp. $429-438$.

30. Van Wart, Montgomery (2005). Dynamics of leadership in public service. (Armonk, NY: M.E. Sharpe).

31. Verschoor,C.C. (2006). Strong ethics is a critical quality of leadership. Strategic Finance, 87, pp. 19-20. 
NOTES 